\title{
JUSTIÇA SOCIAL E LIBERALIZAÇÃO DO COMERCIO INTERNACIONAL
}




\title{
JUSTIÇA SOCIAL E LIBERALIZAÇÃO DO COMÉRCIO INTERNACIONAL ${ }^{1^{*}}$
}

\author{
Alain Supiot \\ Professor emérito do Collège de France \\ Presidente de honra do Institut d'études avancées de Nantes \\ https://www.college-de-france.fr/site/alain-supiot
}

“"Civilizar', no sentido moderno do termo, significa ensinar as pessoas a trabalhar para que possam comprar, trocar e gastar": esta expressa declaração do presidente da Câmara de Comércio de Lyon data do final do século XIX e se inscreve no contexto da empresa colonial. ${ }^{2}$ Ela poderia servir hoje como um lema para a liberalização do comércio internacional em que estão envolvidos, por vontade ou por força, quase todos os Estados do planeta. Essa definição de “civilização" certamente inspiraria o humor cáustico de Antonio Marzal. Não que ele duvidasse das benesses do trabalho, do comércio e da troca, mas ele percebeu claramente a inclinação messiânica que envolve a pretensão moderna de sujeitar o mundo a uma racionalidade econômica pura e universal. Ele foi capaz, ainda, de descrever o processo de racionalização imposto à cultura pela civilização industrial: "a cultura foi esvaziada (secularizada) de qualquer elemento não formalizável ou diretamente racionalizável, ao mesmo tempo que (...) foi substituída (ressacralizada) pelo mito onipresente e onipotente da ciência naqueles dentre os elementos fortes da cultura que mais resistem a desaparecer sem protestar". ${ }^{3}$ Hoje, a globalização tomou o lugar da colonização como horizonte do messianismo ocidental, mas ela continua imbuída da mesma ambição "civilizadora" consistente em "ensinar às pessoas a trabalhar para poder comprar, trocar e gastar" (inclusive aos domingos!). E, hoje como ontem, esse messianismo enfrenta resistências decorrentes de um princípio que não se encontra nas regras que organizaram e implementaram a liberalização do comércio internacional: o princípio de justiça social.

O contraste entre as evoluções respectivas do direito comercial e do direito social é revelador dessas resistências. Enquanto o primeiro se internacionalizou, o segundo continua essencialmente uma questão nacional. Mas não se pode dizer que ele não foi afetado pela

\footnotetext{
$1{ }^{*}$ Este texto é a versão francesa de uma contribuição redigida em 2007 e publicada em espanhol em homenagem à memória do professor Antonio Marzal (Actualidad de la justicia social: liber amicorum em homenaje a Antonio Marzal. Barcelona: Bosch, 2008). Ele desdobra uma breve intervenção oral feita durante o Congresso Mundial da Sociedade Internacional de Direito do Trabalho e da Seguridade Social, que ocorreu em Paris, em setembro de 2006, cujo objetivo era comentar o relatório geral do professor Lance Compa sobre o tema "Liberalização do comércio e direito do trabalho". [Publicado em Droit social, n 2, fevereiro de 2009, p. 131141. Traduzido por Celso N. Kashiura Jr., José César de Magalhães Jr. e Oswaldo Akamine Jr., como parte das atividades do grupo de pesquisa "Interfaces entre direito, Estado e economia". Registramos nossos agradecimentos ao autor e à editora Dalloz, pela autorização para publicação, e, em especial, a Camila Perruso pelo inestimável suporte.]

2 Citado por WESSELING, H. Le partage de l'Afrique. Paris: Denoël, 1996 (reeditado por Folio-Gallimard, 2002, p. 169).

3 MARZAL, A. Análisis politico de la empresa: razón dominante y modelos de empresa. Barcelona: Ariel, 1983, p. 11.
} 
liberalização do comércio. Muito ao contrário, ele é o palco de uma tensão entre duas tendências opostas. De um lado, o direito do trabalho limita a pressão pelo rebaixamento das condições de trabalho operadas por essa liberalização. Mas, por outro lado, ele se desfaz pouco a pouco sob essa pressão e não pode mais garantir um estatuto decente para todos aqueles que vivem do trabalho. Como se sabe, isso se traduz, em termos macroeconômicos, em uma ruptura da ligação entre a produtividade do trabalho e sua remuneração e na atribuição dos ganhos de produtividade aos rentistas e aos especuladores. ${ }^{4} \mathrm{Na}$ senda do mundo do trabalho, essa erosão se exprime pela ampliação da desigualdade de renda e de estatuto e, sobretudo, em um aumento espetacular do trabalho indecente, que espalha por todos os lugares suas diferentes facetas: nos países ricos, no incremento do número de trabalhadores pobres que não obtêm de seus empregos meios para uma vida digna; na adoção da precariedade como modo estrutural de gestão dos "recursos humanos"; na ampliação do setor informal nos países pobres, onde faixas inteiras da população se esforçam para sobreviver na maior indigência e sem qualquer segurança física ou econômica. Conforme as conclusões que a Comissão mundial sobre a dimensão social da mundialização publicou em 2004 sob a égide da OIT, "para uma vasta maioria das mulheres e dos homens, a mundialização não correspondeu às suas aspirações, simples e legítimas, a um trabalho decente e a um futuro melhor para suas crianças". ${ }^{5}$

Essa constatação apenas traduz ao nível dos fatos a espetacular reversão ocorrida no plano dos princípios jurídicos que regem a organização do comércio internacional nos últimos 20 anos. A liberalização do comércio foi erigida como um fim em si mesmo, em detrimento dos objetivos de justiça social fixados no momento imediato após a Segunda Guerra Mundial. Isso resulta em uma esquizofrenia normativa, donde só se pode sair devolvendo à justiça social seu posto de princípio fundante das trocas comerciais em escala internacional.

\section{A inversão de meios e fins}

É forçoso reconhecer que a tentativa de refundar o comércio internacional sob o princípio de justiça social, operada após a Segunda Guerra Mundial, falhou (A) e que a liberalização do comércio procedeu de uma dogmática de competição universal, que conduz a uma ordem jurídica esquizofrênica que justapõe normas de inspiração radicalmente opostas (B).

\section{A - O objetivo de justiça social no comércio internacional}

Ao final da Segunda Guerra Mundial, os dirigentes dos países livres tinham adquirido consciência da imperiosa necessidade de construir uma ordem internacional fundada sob

\footnotetext{
4 Sobre esse movimento de deflação salarial, veja-se GRÉAU, J.L. L'avenir du capitalisme. Paris: Gallimard, 2005, p. 75 e seguintes. 5 COMISSÃO MUNDIAL SOBRE A DIMENSÃO SOCIAL DA MUNDIALIZAÇÃO. Créer des opportunités pour tous. Genebra: OIT, 2004, p. XI. No mesmo sentido, LEE, E.; VIVARELLI, M. Les conséquences sociales de la mondialisation dans les pays en développement. Revue internationale du travail, Paris, v. 145, n. 3, 2008, p. 191-210.
} 
o princípio da dignidade humana e de submeter as regras do comércio internacional a esse princípio. A primeira declaração internacional que assim se referia à dignidade é a de Filadélfia, adotada em 10 de maio de 1944 e integrada depois à Constituição da Organização Internacional do Trabalho. Evocando as terríveis provações pelas quais o mundo acabara de passar, o artigo II dessa declaração começa por repetir, palavra a palavra, a primeira alínea da Constituição da OIT adotada em 1919, segundo a qual "um país perene somente pode ser estável sobre a base da justiça social”. Mas enquanto a Constituição de 1919 deu a esse novo princípio de justiça apenas uma lista de exemplos concretos (limitação à duração da jornada de trabalho, combate ao desemprego e às doenças profissionais etc.), a Declaração de Filadélfia oferece uma definição coerente e compreensível: "todos os seres humanos de qualquer raça, crença ou sexo, têm o direito de assegurar o bem-estar material e o desenvolvimento espiritual dentro da liberdade e da dignidade, da tranquilidade econômica e com as mesmas possibilidades".

Essa definição foi bastante inovadora e, certamente, permanece profética, de muitas maneiras. Em primeiro lugar, ela inovou por seu conteúdo, integralmente marcado pela vontade de romper com o cientificismo e o darwinismo social. Primeira declaração internacional a se referir ao princípio da dignidade, a Declaração de Filadélfia esclareceu seu teor ao ligar o progresso material ao desenvolvimento espiritual. O homem não pode ser reduzido nem ao seu corpo nem ao seu espírito, porque é a unidade dessas duas dimensões que é sua característica específica e que deve ser respeitada, qualquer que sejam sua raça, seu sexo ou suas crenças. Igualmente notável é o objeto do direito assim proclamado, que não se situa sob o registro do ter, mas no do agir: é um "direito buscar" seu progresso material e seu desenvolvimento espiritual, isto é, um direito do trabalhador ao seu desenvolvimento como ser humano. Aqui, não lidamos com um ser programável, mas com um sujeito livre ao qual é preciso garantir as condições de usar de sua liberdade. Tais condições são a igualdade de oportunidades e a segurança econômica, que realmente colocam os homens em posição de agir e, assim, complementam sua capacidade jurídica (fundada sobre a liberdade e a igualdade formais) com uma capacidade de fato. A noção de segurança econômica, aqui, merece especial atenção, porque seu campo de aplicação é muito mais vasto que o da segurança social, que constitui apenas um dos aspectos. Ela cobre as condições mínimas sem as quais não é possível empreender uma atividade econômica (da segurança física e alimentar à segurança jurídica e monetária) e essa segurança, sem a qual não há liberdade econômica, depende sempre da intervenção das instituições públicas.

Em segundo lugar, embora essa definição de justiça social se apresente como a afirmação de um direito individual, os três parágrafos que se referem a ele qualificam sua realização como “principal objetivo de qualquer política nacional ou internacional”. Duas ideias novas aparecem aqui. A primeira é que os direitos universais só têm sentido na medida em que estão inscritos 
em um quadro institucional que lhes permita a realização. Em outras palavras, de nada adianta proclamar tais direitos subjetivos na ausência de um direito objetivo que assim se imponha tanto aos indivíduos quanto aos Estados e às organizações internacionais. A justiça social não se reduz a uma distribuição de direitos individuais porque a busca de sua realização dá sentido ao agir de todos. A segunda novidade é propor o direito não como um limite a não ser cruzado, mas como um objetivo a alcançar, como um horizonte que é preciso visar. Essa noção de finalidade, que figura no próprio título da Declaração de Filadélfia, conheceria, meio século mais tarde, uma fortuna jurídica singular com a ascensão de um "direito regulatório", cuja característica essencial consiste justamente em submeter a liberdade de agir à realização de certos objetivos. A inovação é tão notável que ela leva a Declaração a estabelecer as bases normativas de um procedimento de avaliação permanente da eficácia social da regulação econômica: "quaisquer planos ou medidas, no terreno nacional ou internacional, máxime os de caráter econômico e financeiro, devem ser considerados sob esse ponto de vista e somente aceitos, quando favorecerem, e não entravarem, a realização desse objetivo principal" e "compete à Organização Internacional do Trabalho apreciar, no domínio internacional, tendo em vista tal objetivo, todos os programas de ação e medidas de caráter econômico e financeiro” (art. II-d).

\section{B - A dogmática da competição universal}

Essa hierarquia de meios e de fins foi totalmente derrubada depois de trinta anos. Hoje, o objetivo atribuído ao Estado no nível internacional é o da livre circulação de capitais, de mercadorias e de serviços, assim como o reconhecimento universal dos direitos de propriedade intelectual. As normas sociais só são admitidas na medida em que não pareçam possuir natureza obstaculizante para o alcance dessa finalidade. Testemunha dessa queda, a declaração relativa aos direitos e princípios fundamentais do trabalho adotada em 1998 pela OIT, conclui: "as normas do trabalho não deveriam utilizar-se com fins comerciais protecionistas e (...) nada na presente declaração e seu seguimento poderá invocar-se nem utilizar-se de outro modo com esses fins; ademais, não deveria de modo algum colocar-se em questão a vantagem comparativa de qualquer país sobre a base da presente declaração e seu seguimento". Isso significa que o livre cambismo é um princípio superior à proteção dos trabalhadores e que os direitos, mesmo os fundamentais, devem ceder face às necessidades da competição de todos os homens em todos os países do mundo.

Se a competição econômica é tornada a finalidade última da ordem jurídica, assim é em razão da adesão ao dogma segundo o qual o crescimento da produção e do comércio é um fim em si, e que esse fim não pode ser alcançado senão pela implementação da concorrência generalizada entre todos os países. É pela exposição desse dogma que se abre o acordo de Marraquexe estabelecendo a Organização Mundial do Comércio (OMC). Segundo o primeiro 
parágrafo do preâmbulo desse acordo, as relações entre os Estados no domínio comercial devem "ser orientadas tendo em vista a melhoria dos níveis de vida, a realização do pleno emprego e um aumento acentuado e constante dos rendimentos reais e da demanda efetiva, bem como o desenvolvimento da produção e do comércio de mercadorias e serviços". O contraste com a Declaração de Filadélfia é impressionante. O aumento de indicadores econômicos quantitativos (taxa de emprego, aumento acentuado e constante (sic) de renda e da demanda), e "o desenvolvimento da produção e do comércio de mercadorias e serviços" são tratados aqui como fins em si. Os seres humanos desapareceram da lista de objetivos atribuídos à economia e ao comércio, e com eles toda a referência à sua liberdade, à sua dignidade, à sua segurança econômica e à sua vida espiritual. $\mathrm{O}$ contraste não é menor quanto ao método de realização desses objetivos. Segundo o parágrafo três do preâmbulo, essa realização implica "a conclusão de acordos recíprocos e mutuamente vantajosos tendo em vista a redução substancial dos direitos aduaneiros e de outros entraves ao comércio, bem como a eliminação do tratamento discriminatório nas relações comerciais internacionais". Onde a Declaração de Filadélfia considera as regras comerciais como um meio pelo qual a eficácia deveria ser avaliada tendo em vista os objetivos de dignidade e de segurança econômica atribuídos aos Estados, o acordo da OMC viu desaparecer toda a hierarquização de meios e fins. Não há nenhuma obrigação de avaliar a eficácia real da generalização da livre circulação de capitais e de mercadorias na escala mundial em vista dos objetivos do nível de vida, da taxa de emprego ou de renda. Um elo necessário parece unir a melhora dos indicadores econômicos e o desmantelamento das fronteiras comerciais. O efeito benéfico dele é postulado pelo acordo como uma verdade evidente nela mesma, tornando inútil todo o exame dos efeitos reais do desmantelamento das fronteiras comerciais.

Nessa nova dogmática, a implantação da concorrência se tornou o objetivo e os homens, um simples meio de alcançá-lo. Já não se trata de se perguntar se uma competição comercial ampliou os efeitos benéficos sobre as condições de vida e de trabalho, mas, ao contrário, tratase de se perguntar se as regras sociais não impedem essa competição. Ela deve ser exercida integralmente, tanto entre os homens quanto entre as empresas e os Estados, que devem todos cultivar sua "vantagem comparativa". ${ }^{6}$ Assim, numa recente comunicação relativa a seu plano de ação "Legislar Melhor", 7 a Comissão Europeia parte do princípio de que "o ambiente regulatório da União Europeia" tem por objetivo "promover a competitividade na Europa", por inferir que "as novas iniciativas legislativas devem ser objeto de uma avaliação de impacto", destinada a

6 Sobre a palavra de ordem gerencial inspirada em Ricardo, v. PORTER, M. The competitive advantage of nations. Nova Iorque: Free Press-McMillan, 1990, traduzido para o francês: L'avantage concurrentiel des nations. Paris: Interéditions, 1993. Ver também a crítica de GALBRAITH, J.K. The predator State. Nova Iorque: Free Press, 2008, p. 69 e seguintes.

7 Comunicação Résultat de l'examen des propositions législatives en instance devant le législateur, COM (2005) 462 final. [Disponível em https://eur-lex.europa.eu/legal-content/FR/TXT/?uri=CELEX:52005DC0462]. 
verificar se são essencialmente inclinadas a "contribuir com a competitividade". Apresentando essa comunicação, o vice-presidente do Parlamento europeu explicou que a Comissão havia começado a elaborar, para esse fim, "normas para a nova legislação de avaliação de custos induzidos". Essas "metanormas" serão elaboradas segundo uma "metodologia" baseada na “análise e conhecimentos científicos que alimentam os estudos de impacto graças a uma rede externa de especialistas". ${ }^{8}$ Um filtro normativo "científico" será, assim, colocado previamente à deliberação parlamentar, evitando que os deputados cheguem a conhecer projetos de normas jurídicas prejudiciais à competitividade das empresas. A comunicação contém uma primeira lista de 68 projetos de diretivas retirados sob esse fundamento, dos quais, por exemplo, aquele que impõe o repouso dominical para os transportadores rodoviários.

Uma ordem jurídica que, assim, coloca os bens em uma posição superior aos homens não pode ser sustentável. A constituição de sujeitos deve preceder a definição de suas relações com as coisas, para poder dar significado a suas ações. ${ }^{9}$ Um direito que põe abaixo essa antiga hierarquia entre ser, ter e agir, é um direito que agride os homens e que os encoraja a agredir o direito.

A maneira pela qual ele agride os homens se apresenta, por exemplo, na relevância hoje atribuída ao princípio da livre circulação: ele tende a ser absoluto para os capitais, geral para as mercadorias e nulo para os homens, se forem pobres. Essa diferença de tratamento se encontra nas regras que regem a livre circulação de mercadorias: é proibido ter em conta a maneira pela qual elas foram fabricadas quando se trata de proteger os trabalhadores que as fabricaram, ${ }^{10}$ mas é obrigatório ter em conta quando se trata de defender a propriedade intelectual. ${ }^{11}$ É o mesmo com a segurança: a segurança monetária ou a segurança dos negócios figuram como imperativos categóricos, enquanto a segurança econômica dos homens, quer se trate de segurança de emprego ou de segurança social, é acaloradamente denunciada como um obstáculo à competitividade.

Posto, assim, a serviço das coisas, o direito não pode ser respeitado pelos homens. Essa perda de legitimidade pode ser vista de cima a baixo na escala social. Embaixo, onde vigoram as formas mais extremadas de insegurança econômica e de fragilização da dignidade

\footnotetext{
8 Parlamento europeu. Discurso de Günter VERHEUGEN (Speech/05/541) de 27 de setembro de 2005.

9 Tal é a ordem lógica da exposição das Institutas de Gaio “Omne autem ius quo utimur vel ad personas pertinet, vel ad res, vel ad actiones. Sed prius videamos de personis" ("todos os direitos que usamos se referem a pessoas, coisas e ações. Vejamos, inicialmente, os que concernem às pessoas”). V. GAIUS. Institutas. Trad. fr. J. Reinach. Paris: Les Belles-lettres, 1991, I-8, p. 2.

10 As restrições à livre circulação de mercadorias previstas pelas regras do comércio internacional só podem ser fundadas sobre as características dos produtos finalizados importados e não sobre os processos de produção ou de fabricação. (Para uma apresentação geral dessa regra, v. CARREAU, D.; JULLIARD, P. Droit international économique. Paris: Dalloz, 2003, n. 711, p. 244 e seguintes. E para sua crítica, v. HOWSE, R.; REGAN, D. The product/process distinction - an illusory basis for disciplining "unilateralism" in trade policy. European journal of international law. Florença, v. 11, n. 2, 2000, p. 249-289.

11 Esse é o significado do acordo sobre os Aspects des droits de propriété intellectuelle qui touchent au commerce (ADPIC-TRIPS, em inglês) anexados ao acordo de Marraquexe. Esse acordo tem por efeito organizar os fluxos financeiros dos países pobres para os países ricos, através da implantação de um sistema mundial de arrecadação compulsória de royalties aos titulares de direitos de propriedade intelectual e da destruição de produtos que tenham sido fabricados infringindo-os.
} 
das pessoas, assiste-se a um aumento espetacular de infrações e da violência, que suscita, em resposta, uma inflação de medidas penais e de segurança. No topo, onde tomam assento os guardiões da dogmática econômica, os direitos nacionais do trabalho são tratados como "produtos legislativos", tornando necessário organizar a concorrência para eliminar os menos aptos a responder às expectativas dos investidores. ${ }^{12}$ Tratando o direito não como o quadro normativo no qual se inscreve a competição econômica, mas como um dos objetos dessa competição, essa doutrina repudia toda ideia de justiça social e faz da luta de todos contra todos o único princípio normativo universal. Fazendo assim prevalecer as relações de força sobre as relações de direito, esse darwinismo normativo substitui o liberalismo econômico por um anarco-capitalismo destruidor das bases institucionais da economia de mercado.

\section{Uma ordem jurídica esquizofrênica}

O sistema jurídico no qual se implanta o processo de globalização parece hoje sofrer de esquizofrenia normativa. Ao invés de ligar as dimensões econômicas e sociais desse processo, ele as dissocia justapondo dois tipos de normas que essencialmente se ignoram e em muitos aspectos se contradizem.

\section{A - A fraqueza das regras sociais}

No polo das normas internacionais do trabalho, as convenções da OIT adquiriram uma inegável legitimidade e são invocadas em toda parte. Mas elas padecem de duas fraquezas. A primeira é seu caráter pouco vinculante. As convenções da OIT são numerosas, mas sua força vinculatória é duplamente limitada pelo self-service normativo que elas autorizam (os Estados-membros dessa organização são livres para escolher o que ratificar) e pela ausência de um verdadeiro recurso jurisdicional que permita sancionar sua violação. ${ }^{13}$ Esse self-service normativo e essa falta de sanções efetivas são ainda mais manifestas no caso de compromissos voluntários subscritos pelas empresas sob o título de "responsabilidade social", que se refere frequentemente a certas normas da OIT, cuidadosamente selecionadas.

A segunda fraqueza das normas internacionais do trabalho é a de serem eventualmente desconectadas da realidade das situações locais, sobretudo porque a maioria delas visa apenas o trabalho assalariado, isto é, uma forma de trabalho que permanece minoritária em diversos países, a começar pelos mais povoados. A Declaração da OIT, adotada, em 1998,

12 Cf. o programa "Doing Business", desenvolvido pelo Banco Mundial: http:/www.doingbusiness.org/ExploreTopics/ HiringFiringWorkers/CompareAll.aspx. O Banco retoma aqui uma metodologia desenvolvida por economistas das universidades de Harvard e de Yale: BOTERO, J.; DJANKOV, S.; LA PORTA, R.; LOPEZ-DE-SILANES, F.; SCHLEIFER, A. The regulation of labor. The quarterly journal of economics, Cambridge, v. 119, n. 4, nov. 2004, p. 1339-1382. V., nesse ponto: SUPIOT, A. Le droit du travail bradé sur le "marche des normes". Droit social, Paris, n. 12, 2005, p. 1087.

13 Cf. para uma apresentação recente dos mecanismos de controle de aplicação das normas da OIT: SERVAIS, J.M. Normes internationales du travail. Paris: LGDJ, 2004, n. 983 e seguintes, p. 257 e seguintes. 
para solenemente lembrar a todos os Estados os princípios e direitos fundamentais do trabalho que eles são chamados a respeitar, não menciona a segurança física ou mental, algo que ainda é um dos princípios fundadores do direito do trabalho e cuja prioridade é atestada por todos os estudos sobre todas as formas de trabalho no mundo. Por outro lado, essa declaração vaticina uma "abolição efetiva do trabalho infantil" (art. 2-c), que desconsidera o papel do trabalho na educação das crianças e ignora soberbamente a formulação bem mais pertinente e "universalizável” contida na Carta Africana de Direitos e do Bem-Estar da Criança, de 1990: “A criança é protegida de toda forma de exploração econômica e do exercício de um trabalho que comporte perigo provável ou risco de perturbar sua educação ou que comprometa sua saúde ou seu desenvolvimento físico, mental, espiritual, moral e social” (art. 15-1).

Geralmente, as normas internacionais do trabalho sofrem o prejuízo de serem concebidas como normas "sociais" e de verem sua dimensão econômica ignorada. Assegurar a todos um trabalho decente é uma condição do que hoje é chamado desenvolvimento sustentável. Isso requer homens e mulheres capazes de criar o novo, de formar adequadamente as novas gerações e de atender às necessidades de doentes e idosos. Essa dimensão é mascarada pela oposição, tipicamente ocidental, entre o econômico e o social, algo que leva à compreensão das normas trabalhistas apenas como limites, e até mesmo como entraves, ao livre jogo da economia de mercado, ao passo que, na verdade, elas são uma de suas condições de existência.

\section{B - A incidência social das regras do comércio}

Ao contrário das normas trabalhistas, as normas internacionais do comércio são muito vinculantes. Não é mais uma questão de soft law, mas de dura lex. Os acordos comerciais multilaterais anexados ao acordo de Marraquexe são considerados como parte integrante e são obrigatórios a todos os membros da Organização Mundial do Comércio. Assim, a adesão à OMC não apenas obriga os Estados a abrir suas fronteiras comerciais e financeiras, mas ela os submete à jurisdição de um órgão regulador de litígios que pode lhes condenar, em caso de violação dessa obrigação, a medidas pesadas de retaliação.

Além disso, a liberalização dos mercados de capitais e de mercadorias deu lugar à expansão das normas sociais implícitas que frequentemente têm sentido oposto às normas da OIT. Assim, os planos de ajuste estrutural, aos quais o Fundo Monetário Internacional subordina a concessão de seus créditos, em princípio, não têm por objeto impor um certo padrão de direito do trabalho ou de proteção social no país demandante. Mas, na prática, elas ditam a política dos Estados nesse domínio e seus efeitos sociais desastrosos são, hoje, denunciados frequentemente. Da mesma forma, as normas internacionais de contabilidade, que devem ser respeitadas pelas empresas que buscam abertura de capital, determinam as políticas sociais dessas empresas mais fortemente do que qualquer convenção da OIT. Elaboradas por autoridades 
privadas internacionais, essas normas foram reformadas nos últimos vinte anos, de uma forma que incentiva os dirigentes de empresas a sacrificar o "recurso humano" no altar da "criação de valores mobiliários". ${ }^{14}$ De uma maneira geral, os novos modos de governança, pública ou privada, fazem muito uso de indicadores quantitativos, que são assim os veículos técnicos de uma normatividade disfarçada, que dá uma face técnica e objetiva a escolhas valorativas que são, assim, subtraídas ao debate democrático. ${ }^{15} \mathrm{~A}$ incidência de normas do comércio internacional sobre o trabalho não-assalariado é ainda mais considerável, já que essas normas formam o núcleo duro do que se chama de direito do trabalho autônomo. Muitos exemplos recentes, como o da criação de frangos na África central ${ }^{16}$ ou a cultura de algodão nos países do Sahel, ${ }^{17}$ mostraram como a abertura de fronteiras aos produtos industriais de baixo custo e de qualidade medíocre poderiam arruinar em pouco tempo as chances de desenvolvimento de uma produção local e vir a engrossar as fileiras de candidatos à emigração para os países europeus. As normas do comércio internacional agem, então, como normas sociais por tabela, que permitem ou que proíbem parcelas inteiras da população de um país de viver decentemente de seu trabalho, em contradição patente com os princípios e os objetivos proclamados pela OIT.

Uma das manifestações mais visíveis da incidência social da liberalização do comércio é a migração de uma crescente multidão de pessoas que não encontram mais em seus países meios de viver decentemente de seu trabalho. Essa migração é, em boa parte, ilegal, já que, na ordem jurídica internacional contemporânea, a livre circulação é reservada às coisas e proibida aos homens. Por um lado, a abertura irrestrita das fronteiras aos produtos provenientes de países de níveis econômicos diferentes arruína as condições de vida e de trabalho de milhões de homens e mulheres, tanto nos países do Norte, atingidos pelas “deslocalizações”, como nos países do Sul, cuja agricultura e artesanato não suportam importações maciças de produtos de baixo custo. Nos países muito pobres, para pagar o custo social da liberalização e assegurar um mínimo de subsistência àqueles privados de trabalho, pessoas tentam emigrar para países mais ricos, onde se reivindica a proibição desse movimento e o fechamento das fronteiras para a imigração. Um sistema que condena assim massas humanas inteiras à miséria e concentra riquezas colossais nas mãos de um número muito pequeno de "vencedores" não pode ser um sistema estável, em que cada um fique pacientemente em seu canto. Desse ponto de vista, é irrealista pensar que

14 Cf. JUBÉ, S. Droit social et normalisation comptable. Tese, Universidade de Nantes, 2008.

15 Por exemplo, indexar as políticas públicas à maximização da taxa de emprego incentiva a considerar qualquer trabalho como emprego e, por conseguinte, conduz à desregulamentação do mercado de trabalho. Sobre esse tema, v. SALAIS, Robert. "Acerca de la utilization acertada (y desacertada) de los indicadores en la acción pública”. In: REYNAUD, E.; SUPIOT, A. (orgs.). Protección social y trabajo decente: nuevas perspectivas para las normas internacionales de trabajo. Madrid: La Lay, 2006.

16 V. dossiê publicado sobre o assunto por um coletivo de ONGs, "Exportations de poulets: l'Europe plume l'Afrique" (www.agirici. org/HTML/PDF/Campagnes/Poulets/poulets_print.pdf).

17 Cf. MIROUDOT, S. Quel avenir pour l'initiative sectorielle en faveur du coton après l'echec de Cancún? Mémoire Science Po, Paris, mar. 2004. 
se possa controlar o problema da imigração clandestina por meio da construção de muros e não pela regularização de todos aqueles que conseguem atravessá-los. ${ }^{18}$ Confiar na "seleção natural" daqueles que conseguem escapar do arame farpado ou do afogamento para saber quem terá o direito de trabalhar na Europa não é mais satisfatório que confiar no mercado para classificar os imigrantes autorizados a trabalhar, ${ }^{19}$ e saquear os escassos recursos humanos de trabalhadores qualificados do Sul através de uma política de "imigração seletiva". Na França, a controversa criação de um "Ministério de Imigração, Integração, Identidade Nacional e Co-desenvolvimento", em 2007, simboliza essa nova orientação política que combina, de um lado, o ingresso de trabalhadores estrangeiros, permitindo evitar aumentos de salário em certos setores da economia ${ }^{20}$ e, de outro, um número suficiente de deportações na fronteira para satisfazer a xenofobia engendrada por essa concorrência salarial. As causas profundas das migrações não decorrem do direito social ou do direito penal, mas, sim, da desorganização mundial do comércio. Para uma imensa maioria dos habitantes dos países chamados "em desenvolvimento", mas também para a massa crescente de trabalhadores precários dos países "desenvolvidos", o único direito social que vale seria um direito do comércio internacional que lhes permitisse viver decentemente de seu trabalho. A longo prazo, será difícil escapar de revisões dolorosas e não renunciar ao mito de um mercado sem fronteiras para voltar à ideia sobre a qual a Comunidade Europeia foi fundada, mas que hoje é repudiada: aquela de grandes mercados regionais protegidos por fronteiras comuns e dotados de uma política econômica que lhes permita regular suas trocas com seus vizinhos, em um sentido que reduza as pressões migratórias e possibilite, concomitantemente, a instauração da livre circulação de trabalhadores.

\section{Os caminhos de uma renovação normativa}

Coloca-se, então, a questão de conceber normas que, reestabelecendo a hierarquia entre meios e fins, submetam a circulação de mercadorias e capitais à busca de uma melhora efetiva do destino dos homens.

\section{A. Vincular regras sociais e comerciais}

A resposta aparentemente mais simples a essa questão consiste em estabelecer um

\footnotetext{
18 Estima-se que entre 1995 e 2006, 7.000 latino-americanos morreram tentando atravessar ilegalmente a fronteira com os EUA, mesmo antes deste país decidir construir um muro de $3.200 \mathrm{~km}$ ao longo de sua fronteira com o México. Apenas no correr do mês de agosto de 2006, 4772 africanos chegaram às Canárias, um volume maior que todo o ano de 2005, e 600 corpos de pessoas afogadas tinham sido resgatados desde o início do ano. Durante o primeiro semestre de 2006, 10.000 pessoas chegaram à ilha italiana de Lampedusa, contra apenas 6.900 no ano anterior.

19 Como fez a chamada lei Sarkozy-II, de 24 de julho de 2006, na França, reservando essa autorização para aqueles que conseguem encontrar um emprego "com uma remuneração superior a um limite determinado por decreto": vide Ceseda, art. L 311-11. Essa lei visa reabrir as fronteiras para uma imigração "seletiva" de trabalhadores qualificados, enquanto endurece as condições para a reunificação familiar e a imigração de povoamento.

20 Sobre o caso da construção civil: JUNIN, N. Chantier interdit au public. Enquête parmi les travailleurs du bâtiment. Paris: La Découverte, 2008.
} 
vínculo entre regras sociais e regras comerciais por meio da introdução de uma cláusula social nos acordos comerciais. ${ }^{21}$ Essa cláusula consiste em permitir que um país subordine a abertura de suas fronteiras comerciais ao respeito ao direito fundamental do homem ao trabalho por seus parceiros comerciais. O destino da cláusula social em direito positivo é, como se sabe, paradoxal: formalmente rejeitada no âmbito da OMC, ela prospera no âmbito das uniões aduaneiras regionais e dos acordos de comércio bilaterais. Esse paradoxo provavelmente surpreende aqueles que creem sinceramente no valor universal do livre comércio e na verdade científica dos princípios fundadores da OMC. É, porém, facilmente explicável desde que se tenha em conta a natureza dogmática desses princípios. Uma vez que exprimem não uma verdade econômica inscrita na natureza, mas crenças largamente desconectadas da realidade, é tanto mais difícil implementá-los quanto mais nos aproximamos deles. Por isso, não é surpreendente que essa implementação obrigue, em graus diversos, a redescobrir o caráter artificial da distinção entre as dimensões econômica e social das atividades humanas e a vincular juridicamente tais dimensões. Compreende-se, assim, que os Estados que, na OMC, rejeitaram todas as regras limitadoras da concorrência internacional dos trabalhadores e da vantagem comparativa dos baixos salários ${ }^{22}$ aceitem, em muitos casos, a introdução de uma cláusula social nos acordos comerciais em nível regional ou bilateral.

Essas cláusulas proliferam nos tratados bilaterais de comércio que se difundiram após o impasse das negociações multilaterais conduzidas no âmbito da OMC. ${ }^{23}$ Elas frequentemente limitam-se a um compromisso de cada país fazer respeitar as normas trabalhistas nacionais e são geralmente acompanhadas por procedimentos de resolução de conflitos resultantes de sua aplicação. ${ }^{24}$ No mais, as regras internas de cada país podem subordinar a ratificação desses acordos a um estudo de seu impacto sobre o emprego e os direitos dos trabalhadores. ${ }^{25}$

21 Para uma síntese atualizada do debate sobre a cláusula social, v. MOREAU, M.A. Normes sociales, droit du travail et mondialisation. Paris: Dalloz, 2006, p. 190 e seguintes.

22 Cf. a declaração ministerial adotada em Singapura em dezembro de 1996: "Consideramos que o crescimento econômico e o desenvolvimento promovidos por um incremento nas trocas comerciais e uma maior liberalização do comércio contribuem para a promoção dessas normas [fundamentais do trabalho]. Rejeitamos o uso de normas trabalhistas para fins protecionistas e convimos que a vantagem comparativa dos países, em particular dos países em desenvolvimento com baixos salários, não deve ser questionada."

23 Os vários acordos internacionais assim celebrados pelos Estados Unidos podem ser consultados no site oficial do Office of United States Trade Representatives (http://www.ustr.gov). Para um estudo desses acordos, v. ALSTON, P. "Core labour standards" and the transformation of the international labour rights regime. The european journal of international law, Florença, v. 15, n. 3, 2004, p. 457-521. BURTLESS, G. Workers' rights, labor standards and global trade. The Brookings review, Washington, v. 19, n. 4, 2001, p. 10-13. CHARNOVJTZ, S. The labor trade dimension of the emerging free trade area of the americas. In: ALSTON, P. (ed.). Labour rights as human rights. Oxford: OUP, 2005, p. 143-176. HEPPLE, B. Labour law and global trade. Londres: Hart, 2005. GATTO, A. The integration of social rights concerns in the external relations of the European Union. In: BURCA, G.; DE WITTE, B. (orgs.). Social rights in Europe. Oxford: OUP, 2005, p. 339-365. DOUMBIA-HENRY, C.; GRAVEL, E. Accords de libre-échange et droits des travailleurs: évolution récente. Revue internationale du travail, Genebra, v. 145, n. 3, 2006, p. 211 e seguintes.

24 Cf., por exemplo, as disposições do capítulo 8 do acordo entre Estados Unidos e Chile, que institui um procedimento de análise das falhas desses países em fazer respeitar o direito do trabalho em seus territórios (art. 18.7) e prevê um mecanismo de cooperação entre as duas partes para a efetivação da declaração de 1998 da OIT (art. 18.5). Ademais, para um exemplo mais atual, o acordo celebrado em $1^{\circ}$ de abril de 2007 entre EUA e Coreia do Sul, no qual esses dois países se comprometem a fazer respeitar suas legislações trabalhistas e ambientais e a estabelecer mecanismos que permitam fortalecer sua cooperação nesses domínios.

25 V., nesse sentido, a seção 2102 (c) do Trade Act of 2002 (Public Law 107-210) adotado pelos Estados Unidos. 
As cláusulas sociais introduzidas nos sistemas de preferências comerciais generalizadas ${ }^{26^{*}}$ são mais exigentes. Esses sistemas consistem em oferecer aos países em desenvolvimento um acesso privilegiado ao mercado interno por meio de sua adesão a certas regras em matéria trabalhista, ambiental ou de combate à corrupção. ${ }^{27} \mathrm{~A}$ União Europeia reformulou os diferentes dispositivos adotados com essa finalidade num regulamento único adotado em 2005. ${ }^{28}$ Sob o signo do desenvolvimento sustentável, esse regulamento oferece preferências tarifárias aos "países vulneráveis" que tenham ratificado e implementado uma lista de convenções internacionais relativas aos direitos humanos e dos trabalhadores, ${ }^{29}$ ao meio ambiente e aos princípios da "boa governança". A combinação dessas três dimensões (social, ecológica e institucional) num mesmo instrumento deve ser destacada, pois esclarece vários pontos cegos da dogmática econômica. Essa dogmática crê que o trabalho e a natureza são realmente "produtos" suscetíveis de troca mercantil, ainda que não possam ser tratados como tais senão por meio de ficções jurídicas e de instituições estáveis e confiáveis que em conjunto autorizam e canalizam essa mercantilização. A noção de desenvolvimento sustentável é, nesse contexto, bem-vinda, na medida em que permite lembrar os riscos sociais, ecológicos e políticos aos quais somos expostos por essa dogmática. Mas os sistemas de preferência generalizada, além de terem seu alcance prático ainda muito limitado, apresentam o inconveniente de ter por base uma definição unilateral de desenvolvimento. Uma parte forte impõe o respeito a regras às quais ela mesma não necessariamente se vincula a uma parte fraca, regras cuja formulação não procede dos saberes e da experiência das populações às quais se destinam. A experiência das cláusulas sociais mostra, portanto, os limites de uma abordagem que se limita a vincular normas sociais e comerciais existentes sem colocar em questão o conteúdo dessas normas.

\section{B. Colocar a liberalização do comércio a serviço da justiça social}

Outra via possível, retomando o espírito da Declaração de Filadélfia, seria submeter o conteúdo das normas internacionais ao princípio da justiça social e admitir a livre circulação de capitais e de mercadorias apenas na medida em que efetivamente favoreça o exercício por todos os seres humanos do "direito de assegurar o bem-estar material e o desenvolvimento espiritual dentro da liberdade e da dignidade, da tranquilidade econômica e com as mesmas

\footnotetext{
$26^{*} \mathrm{NT}$ : O sistema de preferências comerciais generalizadas é um instrumento da União Europeia por meio do qual o acesso ao mercado comunitário é facilitado, com redução parcial ou integral de tarifas aduaneiras, sem reciprocidade, para certos produtos de certos países considerados em desenvolvimento. Atualmente, o sistema é regido pelo Regulamento UE $n^{\circ} 978$ de 2012 , disponível em: http://data.europa.eu/eli/reg/2012/978/oj

27 Cf. MOREAU, M. Op. cit., p. 209 e seguintes.

28 Regulamento (CE) no 980/2005 de 27 de junho de 2005. V. DISPERSYN, M. Un nouveau cadre pour la dimension sociale dans le système de préférences généralisées de la Communauté. In: DAUGAREILH, I. (org.). Mondialisation, travail et droits fondamentaux. Bruxelas-Paris: Bruylant-LGDJ, 2005, p. 153 e seguintes.

29 V. regulamento (CE) n 9 980/2005, anexo III, parte A. Trata-se de convenções que dão força normativa aos direitos e princípios fundamentais abrangidos na Declaração da OIT de 1998 (trabalho forçado, trabalho infantil, igualdade homem/mulher, organização e negociação coletiva).
} 
possibilidades”. Nessa perspectiva, a liberalização do comércio não é mais um fim em si, mas apenas um dos meios possíveis de buscar esse objetivo de justiça social. Não mais se trata de articular as normas econômicas e sociais existentes, mas de "consider[á-las] sob esse ponto de vista e somente aceit[á-las], quando favorecerem, e não entravarem, a realização desse objetivo principal”. Essa exigência se aplica tanto às normas comerciais, cujos efeitos sociais devem ser levados em consideração, quanto às normas sociais, que devem ter em conta a internacionalização da atividade econômica e a solidariedade objetiva que atualmente liga os trabalhadores em todo o mundo.

\section{Adotar regras comerciais socialmente responsáveis}

Explorar a dimensão social do direito comercial é, sem dúvida, uma das tarefas mais urgentes para a qual deveria se voltar a doutrina "trabalhista". A política de liberalização do comércio internacional é, de fato, acompanhada por reformas profundas no direito comercial, cujo impacto sobre a segurança, ou, mais precisamente, sobre a insegurança econômica dos trabalhadores é considerável. O que há de comum nessas reformas é a prevalência de uma representação puramente quantitativa e financeira da atividade econômica, em detrimento de se considerar as pessoas e as coisas envolvidas nessa atividade. Essa desconexão quanto às realidades concretas está em ação em três áreas chaves: o direito societário, o direito contábil ${ }^{30^{*}}$ e o direito da concorrência. Seria necessário discuti-las para avaliar essas reformas à luz dos objetivos do trabalho decente para todos.

Nesse sentido, as reformas do direito societário realizadas ao longo de vinte anos em nome da corporate governance consistiram em identificar a empresa com seus acionistas e em substituir a liberdade de empreender pela liberdade de investir como princípio básico do direito comercial. É característica dessa evolução, na França, a lei Strauss-Kahn, que, rompendo com um interdito secular, permitiu que as sociedades recomprem suas próprias ações. ${ }^{31}$ Como observa Jean-Luc Gréau, essas recompras de ações rompem o fundamento lógico da distribuição de dividendos pelas corporações: “O direito de receber dividendos provém do fato de que os compradores iniciais, ao subscreverem as ações emitidas, subvencionaram a empresa ao renunciar a qualquer forma de reembolso do capital. Os direitos dos acionistas são indissociáveis de sua renúncia explícita ao capital subscrito. Ora, se a empresa aceita recomprar as ações das mãos dos seus acionistas, esse fundamento é rompido; em razão do preço acordado para a recompra, é ela que subvenciona a si mesma". ${ }^{32}$ Reduzida à condição de centro de lucro,

\footnotetext{
$30^{*} \mathrm{NT}$ : Na prática jurídica francesa, o direito contábil (droit comptable) é considerado, especialmente a partir da década de 1970, uma área técnica autônoma ou relativamente autônoma. No direito brasileiro, o regramento da produção da contabilidade empresarial está, em sua maior parte, inserido no conjunto mais abrangente do direito societário.

31 Lei n ${ }^{\circ}$ 98-546 de 2 de julho de 1998, que contém diversas disposições de ordem econômica e financeira, art. 41; disposições hoje codificadas nos artigos L 225-206 e seguintes do Código Comercial.

32 GRÉAU, J.L. L'avenir du capitalisme. Paris: Gallimard, 2005, p. 175 (grifos do autor).
} 
a empresa perde a capacidade de empreender, isto é, de projetar-se a longo prazo e de assentar sua rentabilidade sobre bases humanas e materiais sólidas. Indexar o direito societário à figura do empreendedor, mais do que às figuras do rentista ou do especulador, levaria a subordinar o direito dos acionistas de participar da direção da empresa a um real engajamento quanto a servir a seus interesses de longo prazo. Liberadas da ditadura do rendimento a curto prazo, as empresas se mostram efetivamente mais comprometidas em preservar e desenvolver as competências e a criatividade de seu pessoal, o único "recurso" verdadeiramente criador de valor.

Da mesma forma, deve-se avaliar e reconsiderar as reformas do direito contábil realizadas durante as últimas duas décadas. Fundadas sobre o princípio do fair value e elaboradas fora de todo o processo democrático, essas reformas visaram satisfazer as expectativas dos acionistas e incrementar a valorização de mercado das empresas, em detrimento de uma estimativa prudente de seus ativos e passivos. Abriu-se assim um fosso entre a imagem contábil da empresa e a sua situação real. O caso Enron mostrou os riscos catastróficos ensejados por essa desconexão progressiva entre a imagem contábil e os fatos. Esse caso deveria conduzir a um questionamento das bases intelectuais das reformas realizadas e um restauro da função primária das normas contábeis, que é a de chamar a empresa às suas responsabilidades perante todos os seus colaboradores públicos e privados e não a de avaliar sua rentabilidade financeira a curto prazo. ${ }^{33}$

As reformas do direito concorrencial visaram desmantelar todas as regras que levavam em consideração a natureza peculiar de certos produtos ou serviços, bem como as desigualdades econômicas entre os países colocados em competição. Com isso, a concorrência, ao invés de exercer-se entre empresas submetidas às mesmas regras do jogo, é exercida entre países, numa corrida ao menor custo social, fiscal e ambiental. Novamente, uma abordagem não dogmática que avalie os reais efeitos ecológicos e sociais dessas reformas permitiria repensar a livre concorrência como simples instrumento de política econômica, cuja utilização deve depender de sua capacidade de melhorar efetivamente o destino da maioria.

De uma maneira geral, praticamente só na Europa a liberalização do comércio adquiriu esse valor dogmático. Seus dirigentes nela vislumbram a expressão das leis da história e da economia que se impõem a todos e que reduzem os Estados a uma função de acompanhamento (palavra fetiche das políticas sociais europeias) de sua implementação. Os Estados Unidos e os grandes países emergentes, como a China e a Índia, ao contrário, vislumbram um jogo (econômico e político) em que cada um deve apostar segundo as cartas que tem em mãos e cujas regras só devem ser observadas na medida em que não sejam prejudiciais aos interesses nacionais. ${ }^{34}$ Essa

33 Cf. JUBÉ, J. Op. cit.

34 O modo como a Índia recusou os acordos TRIPS para desenvolver uma poderosa indústria farmacêutica é um bom exemplo desse pragmatismo (v. CHAISSE, J. Ensuring the conformity of domestic law with World Trade Organisation law: India as a case study. Nova Deli: French research institutes in India, 2005). Ao menos nesse sentido, o país se mantém fiel a Gandhi, que claramente notou que a abertura descontrolada do mercado indiano aos produtos industrializados britânicos condenaria milhões de indianos ao exílio e à 
diferença tem razões constitucionais. A livre circulação de capitais e de mercadorias é a pedra fundamental dos tratados de fundação da União Europeia, portanto não há de surpreender que os dirigentes europeus tenham nela uma crença verdadeira, enquanto seus homólogos chineses e indianos se contentam em dela servirem-se em benefício de seus interesses.

\section{Propor as bases de uma cidadania social internacional}

Dar à justiça social um lugar central no processo de liberalização do comércio obriga, em segundo lugar, a adaptar o direito do trabalho às novas formas de organização das empresas. O direito do trabalho não poderá servir à realização do objetivo do trabalho decente para todos se ficar cristalizado nas formas herdadas da era fordista ou se, ao contrário, for reduzido a uma técnica de exploração do "recurso humano". Foram desenvolvidos, ao longo dos últimos quinze anos, numerosos trabalhos sobre o futuro do direito do trabalho que, aliás, ressaltam a necessidade de direitos sociais vinculados às pessoas, não apenas aos trabalhadores. ${ }^{35}$ É reconfortante que parceiros sociais e os poderes públicos venham se apropriando, hoje em dia, dessa perspectiva sob terminologias diversas no plano nacional. ${ }^{36}$ Embora proceda de uma inspiração aparentemente próxima (combinar liberdade e segurança), a promoção de uma política de "flexiseguridade" pela Comissão europeia ${ }^{37}$ segue, na verdade, pela via exatamente inversa, que consiste em considerar os homens como um "capital humano" cuja "empregabilidade" deve ser garantida para responder em tempo real às exigências de "criação de valor" que se exprimem nos mercados financeiros. Basta comparar termo a termo os conceitos utilizados nessas duas abordagens (liberdade/flexibilidade - capacidade/empregabilidade - situação profissional/ capital humano) para notar o que as separa: num caso, o ponto de partida é a criatividade dos homens e conjugam-se esforços para construir um direito e uma economia que lhes permitam exprimi-la e satisfazer suas necessidades; no outro, o ponto de partida é a suposta infalibilidade do mercado e conjugam-se esforços para fornecer às empresas um "recurso" humano que responda às suas exigências.

No que diz respeito às normas internacionais do trabalho, o esforço de renovação se limitou à adoção da Declaração dos direitos e princípios fundamentais do trabalho de 1998, sem pôr em causa a ideia de que o estatuto do trabalho, diversamente do estatuto dos capitais e das mercadorias, é um assunto puramente nacional, que concerne à soberania dos Estados.

\footnotetext{
miséria. Mas Gandhi também estava preocupado em estabelecer uma solidariedade entre os trabalhadores ingleses do setor têxtil e os camponeses indianos, o que continua a ser uma abordagem de vanguarda.

35 Cf., para um panorama desses trabalhos: GAUDU, F. La sécurité sociale professionnelle: un seul lit pour deux rêves? Droit social, Paris, n. 4, 2007, p. 393. SUPIOT, A. Lectures étrangères sur le devenir du droit social. Droit social, Paris, n. 11, 2005 , p. $1001-1007$.

36 Cf., no caso francês, o relatório La sécurisation des parcours professionnels do Conselho Econômico e Social, apresentado por E. ARNOULT-BRILL (Paris: Journaux officiels, 2007). [Disponível em https://www.lecese.fr/sites/default/files/pdf/Avis/2007/2007_12_ edith_arnoult_Brill.pdf]

37 Comunicado da Comissão Europeia de 27 de junho de 2007: Towards common principles of flexicurity: more and better jobs through flexibility and security. [Disponível em http://ec.europa.eu/social/BlobServlet?docId=2756]
} 
Assim, permaneceram à sombra os problemas oriundos das solidariedades objetivas que, numa economia aberta, ligam os destinos dos trabalhadores de nacionalidades e países diferentes. Essa solidariedade passiva resulta da liberdade de circulação de capitais e de mercadorias de que gozam as empresas e que em toda parte as incita a exercer uma pressão pelo rebaixamento das remunerações e das condições de trabalho. Ela não poderá se transformar em solidariedade ativa enquanto persistir uma diferença de escala entre os direitos das empresas, que são exercidos no plano internacional, e os direitos dos trabalhadores, que permanecem encerrados na jaula do plano dos direitos nacionais.

Um dos meios de reduzir essa diferença de escala entre direitos econômicos internacionais e direitos sociais nacionais é instituir uma cidadania social internacional, que seria o corolário da livre circulação de capitais e de mercadorias. Teorizada notadamente por Thomas Humphrey Marshall depois da Segunda Guerra Mundial, ${ }^{38}$ a cidadania social engloba todos os direitos e deveres garantidores de uma vida digna a todos os membros de uma determinada sociedade. Sua invenção correspondeu à redescoberta da dimensão física da dignidade humana, ignorada pelas primeiras etapas da democracia. Conjugando-se com a cidadania civil (que garante os direitos e liberdades individuais, especialmente no plano econômico) e a liberdade política (que garante os direitos e as liberdades públicas), ela forma o tripé institucional sobre o qual repousa a economia de mercado numa sociedade democrática. Contudo, ela foi concebida, tal como os direitos sociais que engloba, no plano dos Estados nacionais e a questão que agora se coloca é a do conteúdo que ela poderia adquirir no plano internacional. ${ }^{39}$

a) No plano individual, a cidadania social internacional levaria a vincular direitos à condição de trabalhador, independentemente da nacionalidade e do local de residência. Esses direitos não se reduzem aos direitos fundamentais do Homem ao trabalho enumerados na Declaração da OIT de 1998, mas englobam todos os componentes do trabalho decente. A efetivação do objetivo do trabalho decente no plano internacional é demasiado imperiosa para ser abandonada à soft law e demasiado complexa ou diversificada para ser objeto de uma convenção da OIT do tipo tradicional. Ela exige a invenção de normas internacionais de um novo tipo, que combine, de um lado, a firmeza e a generalidade de princípios diretores que se imponham a todos os Estados membros da OIT e, de outro lado, dispositivos de efetivação que levem em consideração a diversidade de situações e de saberes locais. Retomando as proposições emitidas no domínio da proteção social, ${ }^{40}$ a Conferência Internacional do Trabalho engajou-se nesse sentido, ao colocar em estudo um dispositivo que combina um acordo-quadro (que poderia

38 MARSHALL, T.H.; BOTTOMORE, T. Citizenship and social class. Londres: Pluto, 1992.

39 Nesse sentido, v: MAILLARD, S. L'émergence de la citoyenneté sociale européenne. Aix-en-Provence: PUAM, 2008.

40 Cf. JAVILLIER, J.C.; RÉGENT, S.; REYNAUD, E. Protection sociale et travail décent: nouvelles perspectives pour les normes internationales du travail. Semaine sociale Lamy, Paris, n. 1272, set. 2006. 
ser adotado por ela) que estabeleça os princípios gerais do trabalho decente e acordos nacionais que implementem tais princípios. ${ }^{41}$ Negociados entre OIT, Estados membros e outros parceiros internacionais (instituições financeiras internacionais, bancos de desenvolvimento etc.), esses acordos nacionais estabeleceriam objetivos de trabalho decente fundados na experiência e na representação das populações locais e forneceriam aos Estados signatários uma ajuda técnica e financeira para realizá-los.

A cidadania social internacional agrega aos direitos individuais inerentes à noção de trabalho decente os direitos e as liberdades especificamente vinculados à mobilidade internacional. Aqui, o direito comunitário mostra o caminho, na medida em que não restringe a livre circulação às mercadorias e aos capitais, mas a estende aos trabalhadores. $\mathrm{O}$ vínculo assim estabelecido entre a livre circulação das coisas e a livre circulação dos homens se inscreve na perspectiva de um grande mercado regional e das virtudes pacificadoras atribuídas ao comércio. Essas virtudes não podem ser exercidas se um país é obrigado a abrir suas fronteiras aos produtos estrangeiros enquanto proíbe seus nacionais de sair para se formar e trabalhar no exterior. Toda a agenda bilateral ou multilateral de liberalização do comércio deveria, portanto, comportar um capítulo relativo à livre circulação de trabalhadores que leve em conta os interesses de todos os países participantes. Mais do que um direito de imigração, condenado a misturar a invocação dos direitos humanos e o tráfico de trabalhadores estrangeiros, seria necessário um verdadeiro direito negociado de migrações, isto é, um direito que leve em consideração a situação a longo prazo dos países “prestadores” e dos países “consumidores" de mão-de-obra. ${ }^{42}$ Essa mudança de perspectiva permitiria escapar ao ponto de vista unilateral que caracteriza o direito de imigração e ter uma visão coerente de todas as facetas do fenômeno migratório: o trabalho, mas também a educação, a habitação, a saúde, a vida familiar ou os rendimentos.

Nesse contexto, seria possível fazer da livre circulação de trabalhadores um dos atributos da cidadania social internacional. Não ao modo dogmático da atual livre circulação de capitais e de mercadorias, que apaga as fronteiras, mas, pelo contrário, negociando a sua abertura relativa, tanto para homens quanto para coisas. A edificação de muros nas fronteiras dos países ricos não tem outro efeito senão incitar aqueles que conseguem cruzá-las a se instalar de maneira duradoura nesses países com suas famílias, enquanto uma livre circulação controlada lhes permitiria manter contatos próximos com seus países de origem e acabaria por favorecer a reinstalação nesses países de trabalhadores formados e qualificados.

A ideia de cidadania social internacional levaria, em segundo lugar, à admissão da

41 Cf. CONFERÊNCIA INTERNACIONAL DO TRABALHO. Renforcement de la capacite de l'OIT d'appuyer les efforts déployés par ses membres pour atteindre ses objectifs dans le cadre de la mondialisation. Genebra, BIT, relatório V, 96 ${ }^{\mathrm{a}}$ sessão, p. 22 e seguintes. (Disponível em: http://www.ilo.org/public/french/standards/relm/ilc/ilc96/pdf/rep-v.pdf).

42 Cf. entrevista sobre a política francesa de imigração (com R. Filali Meknassi e O.O. Sidibé), Droit social, Paris, n. 3, 2007, p. 268 e seguintes. 
exportabilidade das prestações sociais. Sabe-se que, no plano comunitário europeu, "o trabalhador assalariado ou não assalariado sujeito à legislação de um Estado-membro tem direito, em relação aos membros da sua família que residam no território de outro Estado-membro, às prestações familiares previstas na legislação do primeiro Estado, como se todos residissem no território deste Estado". ${ }^{43}$ A extensão dessa regra às nacionalidades extracomunitárias surge como solução de bom senso quando se compreende o fenômeno migratório em sua globalidade. Ao invés de induzir o trabalhador imigrado a trazer sua família para a Europa - pois este é o resultado da requisição de residência, com todos os problemas de habitação e de educação suscitados por essa migração familiar -, ele teria a liberdade de manter a família nos países de origem, em que o benefício financeiro dessas prestações seria infinitamente maior em vista das diferenças de custo de vida. Ao invés de alimentar o fluxo migratório Sul-Norte, aumentar-se-ia o fluxo financeiro Norte-Sul criado pelo trabalho do migrante.

b) No plano coletivo, no entanto, a cidadania social internacional importaria no reconhecimento de direitos e deveres novos, quer para os trabalhadores, quer para as empresas.

A Declaração da OIT de 1998 deu um passo nesse sentido ao incluir "a liberdade sindical e o reconhecimento efetivo do direito de negociação coletiva" na lista de "princípios e direitos fundamentais do trabalho". As disposições do art. 28 da carta de direitos fundamentais da União Europeia, adotada em Nice, em 2000, são mais completas e mais explícitas: "Os trabalhadores e as entidades patronais, ou as respectivas organizações, têm, de acordo com o direito comunitário e as legislações e práticas nacionais, o direito de negociar e de celebrar convenções coletivas, aos níveis apropriados, bem como de recorrer, em caso de conflito de interesses, a ações coletivas para a defesa dos seus interesses, incluindo a greve.” Esses textos consagram direitos coletivos em termos que não se limitam ao plano nacional, de modo que os direitos de se organizar, de negociar e de agir coletivamente aparecem como elementos legítimos da cidadania internacional. Mas são declarações privadas, até o presente, de força imperativa. No plano comunitário, a representação coletiva nas empresas transnacionais e a negociação coletiva europeia receberam uma base jurídica, mas não a greve e a ação coletiva, que permanecem, em princípio, da alçada exclusiva dos Estados e que, ademais, a jurisprudência mais recente do TJCE entende submetidas à liberdade de recorrer à terceirização internacional ou à deslocalização. ${ }^{44}$ Resulta que a liberdade sindical e o direito de greve permanecem confinados

43 Regulamento CEE no 1408/71, art. 73.

44 TJCE, 6 de dezembro de 2007, processo C-438/05 (Viking) e TJCE, 18 de dezembro de 2007, processo C-341/05 (Laval), que subordinam o direito de ação coletiva à liberdade de estabelecimento e de prestação de serviço, não obstante a exclusão expressa do direito de greve das competências comunitárias pelo art. 137 do tratado. Sobre esses casos, v. CHAUMETTE, P. Les actions collectives syndicales dans le maillagedes libertés communautaires des entreprises. Droit social, Paris, n. 2, 2008, p. 210-220. ROBIN-OLIVIER, S.; PATAUT, E., Europe sociale ou Europe économique? (à propos des arrêts Viking et Laval). Revue de droit du travail, Paris, fev. 2008, p. 80-88. TEYSSIÉ, B. Esquisse du droit communautaire des conflits collectifs. JCP La semaine juridique - social, Paris, fev. 2008, p. 15. SUPIOT, A. L'Europe gagnée par “l'économie communiste de marché", Revue du MAUSS permanente, Paris, 30 jan. 2008 (disponível em: http://www.journaldumauss.net/spip.php?article283). 
nos limites dos quais a liberdade de empreender se emancipou.

Um tal desequilíbrio entre sindicatos e grandes empresas torna o direito de greve altamente ineficaz. Antes de tudo, porque a massa crescente de trabalhadores precários não pode fazer greve. Além disso, porque a greve não tem sentido senão no face a face entre um empregador claramente identificável e uma coletividade de trabalhadores sob suas ordens. Ora, hoje, essa relação binária muitas vezes falta. As coletividades de trabalho são fragmentadas pela subcontratação, pela terceirização e pelo trabalho temporário. O empregador muitas vezes não é quem realmente decide e quem toma de fato as decisões pode escapar de sua responsabilidade e se esconder atrás da cortina das diferentes sociedades sob sua dependência econômica. Desse modo, a greve tende a se tornar a arma dos fortes, ao passo que os fracos são dela privados. Os pilotos da Air France podem fazer greve, mas não os carregadores terceirizados de Roissy, atingidos por decretos de requisição..$^{4546^{*}}$ As tensões resultantes da exploração do trabalho, não mais podendo ser manifestas no campo social, acabam expressas em bases identitárias. Daqueles abandonados pela representação e pela ação coletiva provêm os grandes batalhões para as associações religiosas e étnicas que atualmente florescem.

Este seria um vasto canteiro de obras, que Antonio Marzal ajudou a abrir com seus últimos trabalhos. ${ }^{47}$ Sobre o direito de greve, por exemplo, seria possível admitir que, no setor privado, ele suspenda os contratos precários e, no setor público, não se imponham restrições à greve senão aos trabalhadores sob estatuto público. Mais amplamente, conviria explorar as formas de ação coletiva ternárias, que mobilizam tanto consumidores quanto investidores e são uma arma adaptada às formas atuais de exercício da liberdade de empreender. E, nesse sentido, abrir amplamente a paleta de ações coletivas internacionais, que podem exprimir a solidariedade entre trabalhadores dos países do Norte e dos países do Sul.

c) A cidadania social internacional tem, por fim, vocação para aplicar-se às empresas que gozam da livre circulação internacional de capitais e de mercadorias. Sabe-se que certas empresas nessa condição, para prevenir o risco de ter sua imagem manchada pela violação dos direitos fundamentais daqueles que trabalham direta ou indiretamente para elas, reclamam

\footnotetext{
45 A requisição foi utilizada em outubro de 2005 para interromper uma greve desses assalariados, cujo objeto era uma melhora da remuneração e das condições de trabalho. Eles foram "convidados" a retornar ao trabalho, sob pena de seis meses de prisão e 10.000 euros de multa. Desse modo, obrigação de continuidade do serviço que se impõe aos trabalhadores precários e terceirizados é muito mais forte do que aquela imposta aos funcionários. Para justificar sua decisão, o prefeito de Seine Saint-Denis destacou o "elevado risco terrorista" num período de Plano Vigipirate. Na verdade, são privações de direitos sociais constitucionais desse gênero que elevam o risco de terrorismo, vez que forçam os interessados a abandonar o registro sindical pelo registro religioso e identitário. Um ano depois, o mesmo prefeito proibiu o acesso de carregadores de confissão muçulmana a certas zonas sensíveis (Conselho de Estado, 23 de fevereiro de 2007, $\mathrm{n}^{\circ}$ 299208). O vínculo entre insegurança do estatuto profissional e insegurança pública é aqui evidente.

$46{ }^{*} \mathrm{NT}$ : O decreto de requisição (arrêté de réquisition) é um mandado emitido por autoridade administrativa. No caso, trata-se de mandado para retorno ao trabalho emitida pelo prefeito (préfet) da localidade. O plano Vigipirate (vigilance et protection des installations contre les risques d'attentats terroristes à l'explosif) é um dispositivo de exceção, criado em 1978, que permite a mobilização extraordinária da polícia e das forças armadas francesas para combate ao terrorismo.
}

47 V. MARZAL, A. (ed.). La huelga hoy en el derecho social comparado. Barcelona: J.M. Bosch, 2005. 
princípios de responsabilidade social. ${ }^{48}$ Essa responsabilidade é mais marketing do que direito; as empresas envolvidas insistem no caráter voluntário, e não coercitivo, dos compromissos que assumem. É duvidoso, porém, que esse caráter puramente voluntário sirva para protegê-las contra medidas jurisdicionais, na medida em que muitas ordens jurídicas nacionais reconhecem a regra Tu patere legem quam ipse fecisti, que permite aos juízes atribuir obrigatoriedade aos compromissos unilaterais. Noutras palavras, a responsabilidade social, que é ainda hoje apenas um sintoma da vertigem institucional que toma as empresas recentemente emancipadas da ordem dos Estados nacionais, pode amanhã tornar-se um dos elementos de uma cidadania internacional. Essa cidadania das empresas estabeleceria, em correspondência com os novos direitos e liberdades de que as empresas gozam na cena internacional, obrigações em matéria de exploração de recursos humanos e naturais.

Dentre as obrigações que lhes poderiam ser impostas, um lugar de destaque deve ser dado àquelas que decorrem diretamente da declaração universal dos direitos humanos, em especial dos direitos econômicos e sociais proclamados em seus artigos 22 a 25 (segurança social, igualdade de tratamento, trabalho que permita viver dignamente, liberdade sindical, limitação da jornada de trabalho). A tais direitos corresponde o dever de contribuir por imposto ou por contribuições sociais com os mecanismos de solidariedade que condicionam seu exercício. ${ }^{49}$ Esse dever é certamente parte da cidadania internacional das empresas, de modo que, quando elas usam a livre circulação de capitais e de mercadorias para escapar de sua obrigação de contribuir com os sistemas nacionais de solidariedade, elas não apenas abusam de sua liberdade (tal como uma empresa que recorre à falsificação para não pagar os direitos de propriedade intelectual), mas violam os direitos humanos. Assim, a referência à cidadania internacional das empresas permitiria caracterizar as situações nas quais uma empresa abusa das liberdades que lhe são reconhecidas por tratados de comércio. Quando, por exemplo, uma empresa europeia investe na China para fabricar produtos destinados ao mercado chinês, esse uso da liberdade de circulação de capitais serve ao emprego e à produção de bens úteis aos habitantes daquele país, em conformidade com os objetivos fixados pela Declaração de Filadélfia. Quando, ao contrário, esse investimento visa fabricar produtos destinados à reimportação para a Europa, sem pagar os salários e as contribuições sociais e fiscais ali em vigor, configura-se um abuso da liberdade de circulação de mercadorias e um atentado aos direitos humanos. Nessa hipótese, a Europa deveria poder submeter essas reimportações ao pagamento de taxas equivalentes ao montante

\footnotetext{
48 Para um panorama recente, com numerosas indicações bibliográficas, v. BERNS, T. et al. Responsabilités des entreprises et corégulation. Bruxelas: Bruylant, 2007.

49 Esse dever está explicitamente formulado na Declaração Americana dos Direitos e Deveres do Homem de 1948 (art. 35 : toda pessoa está obrigada a cooperar com o Estado e com a coletividade na assistência e previdência sociais, de acordo com as suas possibilidades e com as circunstâncias; art. 36: toda pessoa tem o dever de pagar os impostos estabelecidos pela lei para a manutenção dos serviços públicos).
} 
dos encargos sociais dos quais a empresa buscou escapar. Vê-se por esse exemplo o que poderia significar um retorno ao espírito da Declaração de Filadélfia: certamente não a abolição da liberalização do comércio internacional, mas uma liberalização temperada e controlada, que serve à melhora, e não à degradação, do destino da maioria. 